\title{
The individualized selection of Pancreaticoenteric anastomosis in Pancreaticoduodenectomy
}

\author{
Ke-Min $\operatorname{Jin}^{\dagger}$, Wei Liu ${ }^{\dagger}$, Kun Wang, Quan Bao, Hong-Wei Wang and Bao-Cai Xing ${ }^{*}$ (D)
}

\begin{abstract}
Background: The mortality following pancreaticoduodenectomy has markedly decreased but remains an important challenge for the complexity of operation and technical skills involved. The present study aimed to clarify the impact of individualized pancreaticoenteric anastomosis and management to postoperative pancreatic fistula.

Methods: Data from 529 consecutive pancreaticoduodenectomies were retrospectively analysed from the Hepatobiliary and Pancreatic Surgery Unit I, Peking Cancer Hospital. The pancreaticoenteric anastomosis was determined based on the pancreatic texture and diameter of the main pancreatic duct. The amylase value of the drainage fluid was dynamically monitored postoperatively on days 3,5 and 7. A low speed intermittent irrigation was performed in selected patients. Intraoperative and postoperative results were collected and compared between the pancreaticogastrostomy (PG) group and pancreaticojejunostomy (PJ) group.

Results: From 2010 to 2019, 529 consecutive patients underwent pancreaticoduodenectomy.

Pancreaticogastrostomy was performed in 364 patients; pancreaticojejunostomy was performed in 150 patients respectively. The clinically relevant pancreatic fistula (CR-POPF) was $9.8 \%$ and mortality was zero. The soft pancreas, diameter of main pancreatic duct $\leq 3 \mathrm{~mm}, \mathrm{BMl} \geq 25$, operation time $>330$ min and pancreaticogastrostomy was correlated with postoperative pancreatic fistula significantly. The CR-POPF of PJ was significantly higher than that of PG in soft pancreas patients; the operation time of PJ was shorter than that of PG significantly in hard pancreas patients. Intraoperative blood loss and operation time of PG was less than that of PJ significantly in normal pancreatic duct patients $(p<0.05)$.
\end{abstract}

Conclusions: Individualized pancreaticoenteric anastomosis should be determined based on the pancreatic texture and pancreatic duct diameter. The appropriate anastomosis and postoperative management could prevent mortality.

Keywords: Pancreaticoduodenectomy anastomosis POPF

\footnotetext{
* Correspondence: xingbaocai88@sina.com

${ }^{\dagger}$ Ke-Min Jin and Wei Liu contributed equally to this work.

Key Laboratory of Carcinogenesis and Translational Research (Ministry of

Education/Beijing), Department of Hepatobiliary and Pancreatic Surgery Unit

I, Peking University Cancer Hospital \& Institute, No. 52, Fu-Cheng Road,

Beijing 100142, PR China
}

C The Author(s). 2020 Open Access This article is licensed under a Creative Commons Attribution 4.0 International License, which permits use, sharing, adaptation, distribution and reproduction in any medium or format, as long as you give appropriate credit to the original author(s) and the source, provide a link to the Creative Commons licence, and indicate if changes were made. The images or other third party material in this article are included in the article's Creative Commons licence, unless indicated otherwise in a credit line to the material. If material is not included in the article's Creative Commons licence and your intended use is not permitted by statutory regulation or exceeds the permitted use, you will need to obtain permission directly from the copyright holder. To view a copy of this licence, visit http://creativecommons.org/licenses/by/4.0/. The Creative Commons Public Domain Dedication waiver (http://creativecommons.org/publicdomain/zero/1.0/) applies to the data made available in this article, unless otherwise stated in a credit line to the data. 


\section{Background}

Pancreaticoduodenectomy (PD) remains the golden standard for periampullary cancers [1]. Due to the complexity of the procedures and postoperative lifethreatening complications, the mortality rates still was $1.4-29 \%$ [2, 3]. Despite a significant improvement in postoperative outcomes during recent decades, only a limited number of reports have documented zero mortality in consecutive pancreaticoduodenectomy series.

Postoperative pancreatic fistula (POPF) is one of the most potentially fatal complication after $\mathrm{PD}$ with rate ranging from 40 to $70 \%$, which might cause arterial bleeding and mortality rate to $11-60 \%$ [4-6]. The established risk factors for POPF included a small pancreatic duct size, a soft pancreas and its posterior location. There have been a number of reported managements to reduce the incidence of POPF. The approach to management of the pancreatic remnant and form of pancreaticoenteric anastomosis (PA) determined the chance of developing POPF. Many efforts have been made to improve technical considerations through various modifications of pancreaticojejunostomy (PJ) and reconstruction with pancreaticogastrostomy (PG). The prompt management of POPF also decreased mortality, included in prophylactic use of octreotide and antibiotics.

Despite numerous trials comparing diverse PA techniques and other adjunctive strategies (pancreatic duct stenting, somatostatin analogues, etc), currently, there is no clear consensus regarding the ideal method of PA. The present study aimed to verify our management of individualized PA during operation and intermittent irrigation.

\section{Methods}

\section{Study population}

Between 1st November 2010 and 30th December 2019, 529 consecutive PDs were performed in the Hepatobiliary and Pancreatic Surgery Unit I of Peking Cancer Hospital. No 90-day mortality was reported in any of the 529 patients. Preoperative data were recorded, including demographics, comorbidity, performance status, American Society of Anaesthesiologists (ASA) level, previous abdominal history, preoperative serous bilirubin level and preoperative biliary drainage. The cases included 52 benign diseases (9.83\%) and 477 malignancies (90.17\%).

\section{Surgical techniques}

The texture of pancreatic parenchyma and the diameter of main pancreatic duct were assessed intraoperatively, which determined method of individualized PA. The texture was recorded as soft if elasticity of the pancreas was preserved (the stiffness of the patient's forehead as the reference as mentioned before). Additionally, the diameter of the main pancreatic duct was measured at the surgically transected surface of the pancreas. PG was performed in patients with a normal main pancreatic duct $(\leq 3 \mathrm{~mm})$ and/or soft pancreas texture because the occurrence of clinically significant postoperative pancreatic fistula is more likely in such patients. It was performed with a two-layer purse-string suture on the posterior gastric wall, and the pancreas was mobilized 2$3 \mathrm{~cm}$ to be telescoped into the gastric cavity. PJ was performed in patients with the main duct was larger than 3 $\mathrm{mm}$ and hard pancreatic texture. It was performed with end-to-side two-layer sutures. The first layer was a ductto-mucosa anastomosis, and the second-layer suture was located between the capsule of the pancreas and the seromuscular layer of the jejunum. A pancreatic duct stent was routinely used in all pancreaticodigestive reconstructions for internal drainage. For adequate drainage, two 20F Robinson drains were placed in addition to the pancreaticodigestive anastomosis.

\section{Postoperative management}

The amylase level of the drainage fluid was routinely evaluated on postoperative days 3, 5 and 7. POPF was defined as any measurable drainage on postoperative day 3 with an amylase content greater than 3 times the upper limit of the normal serum amylase level, and the severity was also graded as A, B, or C according to the criteria proposed by the International Study Group on Pancreatic Fistula ${ }^{6}$. If the fluid was transparent with normal amylase level, the drains were removed as soon as possible, typically on postoperative days 8 . The drains were maintained for longer if patients had high drain amylase activity, copious fluid output or effluent with an unfavorable appearance (dark brown, greenish, milky or murky). Antibiotics were selected based on the susceptibility of bacteria isolated from drain fluids. At meanwhile, an irrigating tube was placed along the drainage tube and a low-speed intermittent irrigation was performed until the drain fluid returned transparent, which intended to dilute concentrated amylase. The speed of the irrigating saline should be controlled to avoid it spread into uninvolved areas of the abdominal cavity. When intra-abdominal collection and associated symptoms were detected, ultrasound-guided percutaneous drainage was performed. Irrigation was stopped, and the drainage was removed when the daily collections decreased $<30 \mathrm{~mL} / 24 \mathrm{~h}$. Postoperative complications were graded by the Clavien-Dindo classification [7].

\section{Statistical analysis}

Continuous variables were summarized as the medians and ranges, and categorical variables were summarized as frequencies and percentages. The Mann-Whitney $U$ test was used to compare the continuous variables, and the Chi-square test was used to compare the categorical 
Table 1 Demographic and comorbidity data

\begin{tabular}{ll}
\hline & Number(\%)/median (range) \\
\hline Age (years) & $61(18-82)$ \\
$\quad$ Male & \\
Female & $294(55.6 \%)$ \\
COPD & $235(44.4 \%)$ \\
DM & $14(2.6 \%)$ \\
HBP & $94(17.8 \%)$ \\
PS & $151(28.5 \%)$ \\
$\quad 0-1$ & \\
$2-3$ & $501(94.7 \%)$ \\
ASA & $28(5.3 \%)$ \\
1 & \\
2 & $52(9.8 \%)$ \\
3 & $436(82.4 \%)$ \\
$\quad 4$ & $40(7.6 \%)$ \\
History of abdominal surgery & $1(0.2 \%)$ \\
CAD & $108(20.4 \%)$ \\
Cerebral vessel disease & $26(4.9 \%)$ \\
Previous chemotherapy or radiotherapy & $20(3.8 \%)$ \\
Preoperative biliary drainage & $157(29.7 \%)$ \\
Preoperative hyperbilirubinemia & $246(46.5 \%)$ \\
Weight loss & $290(54.8 \%)$ \\
Smoking & $162(30.6 \%)$ \\
Alcohol abuse & $105(19.8 \%)$ \\
\hline COPD & $23.3 \%)$ \\
\hline
\end{tabular}

COPD chronic obstructive pulmonary disease, $H B P$ hypertension, $D M$ diabetes mellitus, $P S$ performance status, CAD coronary artery disease, ASA American Society of Anaesthesiologists

variables. A $p$ value of $<0.05$ was deemed statistically significant.

\section{Results}

Patient characteristics and surgical details

The demographic and comorbidity data were shown in Table 1 . The median age of all patients was 61 years old (range: 18-82). Two hundred and ninety-four patients (55.6\%) were male. The most common disease was pancreatic ductal adenocarcinoma (130 cases, 24.6\%) (Supplementary Table 1). The median operation time was 287 min (range: 150-648 min), and the median intraoperative blood loss was $200 \mathrm{ml}$ (range: $50-1500 \mathrm{ml}$ ). The median postoperative length of the hospital stay was 19 days (range: 8-121 days) (Table 2).

\section{Postoperative complications}

As shown in Table 2, postoperative complications according to the Clavien-Dindo classification system
Table $\mathbf{2}$ Intraoperative variables and postoperative complications

\begin{tabular}{|c|c|}
\hline Variables & Median (range)/number(\%) \\
\hline Operation time (min) & $287(150-648)$ \\
\hline Intraoperative blood loss (ml) & $200(50-1500)$ \\
\hline Transfusion & $68(12.9 \%)$ \\
\hline RBC transfused(U) & $4(2-20)$ \\
\hline \multicolumn{2}{|l|}{ Pancreatic remnant anastomosis } \\
\hline PJ & $150(28.4 \%)$ \\
\hline$P G$ & $364(68.8 \%)$ \\
\hline No anastomosis & $15(2.8 \%)$ \\
\hline Combined PV-SMV or IVC resection & $20(3.8 \%)$ \\
\hline \multicolumn{2}{|l|}{ Operation types } \\
\hline PD & $436(82.4 \%)$ \\
\hline PD combined devisceration & $78(14.7 \%)$ \\
\hline TP & $10(1.9 \%)$ \\
\hline TP combined devisceration & $5(0.9 \%)$ \\
\hline Morbidity & $311(58.8 \%)$ \\
\hline \multicolumn{2}{|l|}{ Clavien-Dindo classification } \\
\hline 1 & $51(9.6 \%)$ \\
\hline$\|$ & 183(34.6\%) \\
\hline Illa & $56(10.6 \%)$ \\
\hline $111 \mathrm{~b}$ & $11(2.1 \%)$ \\
\hline IVa & $10(1.9 \%)$ \\
\hline DGE & $77(14.6 \%)$ \\
\hline B & $22(4.2 \%)$ \\
\hline C & $55(10.4 \%)$ \\
\hline PPH & $77(14.6 \%)$ \\
\hline A & $4(0.8 \%)$ \\
\hline B & $63(11.9 \%)$ \\
\hline $\mathrm{C}$ & $10(1.9 \%)$ \\
\hline Bile leakage & $21(4.0 \%)$ \\
\hline Pneumonia & $12(2.3 \%)$ \\
\hline Abdominal infection & $84(15.9 \%)$ \\
\hline Urinary tract infection & $3(0.6 \%)$ \\
\hline Wound infection & $5(0.9 \%)$ \\
\hline Arrhythmia & $10(1.9 \%)$ \\
\hline Postoperative pancreatic fistula & $204(38.6 \%)$ \\
\hline A & $152(28.7 \%)$ \\
\hline B & $46(8.7 \%)$ \\
\hline C & $6(1.1 \%)$ \\
\hline Percutaneous drainage & $53(10.0 \%)$ \\
\hline RBC transfusion & $124(23.4 \%)$ \\
\hline RBC transfused(U) & $4(2-30)$ \\
\hline Relaparotomy & $16(3.0 \%)$ \\
\hline Readmission & $6(1.1 \%)$ \\
\hline Postoperative hospital stay (days) & 19(8-121) \\
\hline
\end{tabular}

PV-SMV portal vein-superior mesenteric vein, IVC inferior vena cava, $P D$ pancreaticoduodenectomy, TP total pancreatectomy, DGE delayed gastric emptying, $P P H$ postpancreatectomy haemorrhage, $R B C$ red blood cell 
occurred in 311 patients (58.8\%). POPF occurred in 204 patients (38.6\%), with grade A POPF in 152 patients (28.7\%), grade B POPF in 46 patients $(8.7 \%)$, and grade $\mathrm{C}$ POPF in 6 patients (1.1\%). POPF relating abdominal hemorrhage developed in 9 patients. Among of them, 3 patients underwent angiopraphy and embolization, 5 patients underwent reoperation and one patient received conservative treatment. Twenty-one patients (4.0\%) experienced bile leakage after the operation. Abdominal infection occurred in 84 patients (15.9\%) and 53 patients (10.0\%) received percutaneous drainage. One hundred and twenty-four patients $(23.4 \%)$ received a postoperative $\mathrm{RBC}$ transfusion, and the median number of transfused RBCs was 4 units (range: 2-30 units).

\section{PG versus PJ}

The treatment groups were balanced in terms of most clinical factors and surgical details. However, the hard pancreas (PJ vs. PG, $88.0 \%$ vs. $15.4 \%, p<0.001$ ) and dilated pancreatic duct rates (PJ vs. PG, $65.3 \%$ vs. $13.5 \%$, $p<0.001)$ were significantly different between the 2 groups (Table 3 ). The PJ group patients also had a significantly higher percentage of pancreatic ductal adenocarcinoma or chronic pancreatitis than the PG group (50.0\% vs. $18.1 \%, p<0.001)$. The incidence of POPF was $42.6 \%$ after PG and $32.7 \%$ after PJ $(p=0.037)$. Soft pancreas texture, a normal pancreatic duct size, obesity, longer operation time and pancreaticogastrostomy were significant factors affecting POPF, with estimated odds ratios of $3.191(p<0.001), 3.928(p<0.001), 1.976(p=$ $0.001), 1.635(p=0.040)$ and $0.323(p=0.001)$ respectively (Table 4). In the subgroup analysis according to pancreas texture, the CR-POPF of PJ was higher than that of PG significantly in patients with soft pancreas texture $(p=0.033)$. The operation time of PJ was shorter than that of PG significantly in patients with hard pancreas texture $(p=0.035)$ (Table 5$)$. In the subgroup analysis according to pancreatic duct size, intraoperative blood loss and operation time of PG was less than that of PJ significantly in patients with normal main pancreatic duct $(p<0.05)$ (Table 6).

\section{Discussion}

The present study reported 529 consecutive PDs, representing the largest consecutive study of PD without mortality. Although the occurrence of pancreatic fistulas was $38.6 \%$, routine evaluation of amylase level of the drainage fluid and intermittent irrigation through drainage tube might prevent POPF related mortality. Recent advances in surgical techniques and adequate management of postoperative complications have led to improved clinical outcomes of PD, and the mortality following PD has decreased to below 6\% [8]. POPF is a main source of major morbidity due to the intraperitoneal release of
Table 3 Comparison of the perioperative variables of the PJ and PG groups

\begin{tabular}{|c|c|c|c|}
\hline & PJ(150) & $P G(364)$ & $\mathrm{p}$ \\
\hline MPD diameter(> 3 mm) & $98(65.3 \%)$ & $49(13.5 \%)$ & $<0.001$ \\
\hline Pancreatic texture (hard) & $132(88.0 \%)$ & $56(15.4 \%)$ & $<0.001$ \\
\hline Gender (male) & $89(59.3 \%)$ & 196(53.8\%) & 0.255 \\
\hline Pathology (PDAC or CP) & $75(50.0 \%)$ & $66(18.1 \%)$ & $<0.001$ \\
\hline $\mathrm{BMI}$ & $23.5 \pm 3.2$ & $23.6 \pm 3.3$ & 0.628 \\
\hline ASA & & & 0.329 \\
\hline 1 & $10(6.7 \%)$ & $40(11.0 \%)$ & \\
\hline 2 & $131(87.3 \%)$ & $294(80.8 \%)$ & \\
\hline 3 & $8(6.0 \%)$ & $29(8.0 \%)$ & \\
\hline 4 & 0 & $1(0.3 \%)$ & \\
\hline COPD & $3(2.0 \%)$ & $11(3.0 \%)$ & 0.767 \\
\hline DM & $27(18.0 \%)$ & $61(16.8 \%)$ & 0.734 \\
\hline HBP & $45(30.0 \%)$ & $101(27.7 \%)$ & 0.607 \\
\hline History of abdominal surgery & $35(23.3 \%)$ & $67(18.4 \%)$ & 0.203 \\
\hline Preoperative biliary drainage & $50(33.3 \%)$ & $104(28.6 \%)$ & 0.284 \\
\hline Preoperative hyperbilirubinemia & 87(58.0\%) & $157(43.1 \%)$ & 0.002 \\
\hline Operation time (min) & $296.4 \pm 58.9$ & $288.7 \pm 65.3$ & 0.211 \\
\hline Intraoperative blood loss (ml) & $276.0 \pm 186.2$ & $236.4 \pm 169.8$ & 0.010 \\
\hline Postoperative hospital stay (days) & $21.6 \pm 12.2$ & $24.2 \pm 14.4$ & 0.056 \\
\hline Complications & $78(52.0 \%)$ & $229(62.9 \%)$ & 0.022 \\
\hline POPF & $49(32.7 \%)$ & $155(42.6 \%)$ & 0.037 \\
\hline Grade A POPF & $32(21.3 \%)$ & $120(33.0 \%)$ & 0.009 \\
\hline Grade B/C POPF & $17(11.3 \%)$ & $35(9.6 \%)$ & 0.557 \\
\hline Relaparotomy & $1(0.7 \%)$ & $15(4.1 \%)$ & 0.048 \\
\hline DGE & 19(12.7\%) & $58(15.9 \%)$ & 0.345 \\
\hline PPH & $23(15.3 \%)$ & $51(14.0 \%)$ & 0.698 \\
\hline
\end{tabular}

$P J$ pancreaticojejunostomy, $P G$ pancreaticogastrostomy, MPD main pancreatic duct, $P D A C$ pancreatic ductal adenocarcinoma, $B M I$ body mass index, $A S A$ American Society of Anaesthesiologists, COPD chronic obstructive pulmonary disease, DM diabetes mellitus, HBP hypertension, DGE delayed gastric emptying, $P P H$ postpancreatectomy haemorrhage, $C P$ chronic pancreatitis, POPF Postoperative pancreatic fistula

enterokinase and activation of pancreatic proenzymes resulting in sepsis and haemorrhage. This complication might be inevitable and still causes troublesome shortterm outcomes after surgery.

The approach to management PA remains key factor in determining the chance of developing a POPF. Despite multiple randomized studies and meta-analyses, there is no clear evidence or universally accepted guidelines for how to construct the optimal PA after PD. [9] The multiple studies described above have failed to provide definitive, consistent, and convincing level 1 evidence that any one technique of PA is better than the others, either during the traditional open PD or more recently with the laparoscopic PD. Therefore, it should be 
Table 4 Logistic Regression Analysis of factors affecting POPF

\begin{tabular}{|c|c|c|c|c|c|c|}
\hline \multirow[t]{2}{*}{ Parameter } & \multicolumn{2}{|c|}{ Univariate Analysis } & \multirow[t]{2}{*}{$P$} & \multicolumn{2}{|c|}{ Multivariate Analysis } & \multirow[t]{2}{*}{$P$} \\
\hline & Odds Ratio & $95 \% \mathrm{Cl}$ & & Odds Ratio & $95 \% \mathrm{Cl}$ & \\
\hline Gender & & & 0.153 & & & \\
\hline Female & 1 & & & & & \\
\hline Male & 0.771 & $0.539-1.102$ & & & & \\
\hline Gland texture & & & $<0.001$ & & & $<0.001$ \\
\hline Hard & 1 & & & 1 & & \\
\hline Soft & 2.787 & $1.877-4.138$ & & 3.191 & $1.695-6.008$ & \\
\hline Pathology & & & $<0.001$ & & & 0.15 \\
\hline PDAC or CP & 1 & & & 1 & & \\
\hline Others & 2.635 & $1.704-4.077$ & & 1.605 & $0.842-3.058$ & \\
\hline pancreatic duct diameter & & & $<0.001$ & & & $<0.001$ \\
\hline$>3 \mathrm{~mm}$ & 1 & & & 1 & & \\
\hline$\leq 3 \mathrm{~mm}$ & 4.14 & $2.601-6.591$ & & 3.928 & $2.217-6.961$ & \\
\hline Intraoperative blood loss & & & 0.814 & & & \\
\hline$\leq 400 \mathrm{ml}$ & 1 & & & & & \\
\hline$>400 \mathrm{ml}$ & 1.076 & $0.582-1.992$ & & & & \\
\hline Age & & & 0.725 & & & \\
\hline$<70$ & 1 & & & & & \\
\hline$\geq 70$ & 0.913 & $0.550-1.516$ & & & & \\
\hline BMI & & & $<0.001$ & & & 0.001 \\
\hline$<25$ & 1 & & & 1 & & \\
\hline$\geq 25$ & 2.068 & $1.421-3.008$ & & 1.976 & $1.326-2.945$ & \\
\hline ASA score & & & 0.4 & & & \\
\hline $1-2$ & 1 & & & & & \\
\hline $3-4$ & 0.743 & $0.303-1.134$ & & & & \\
\hline Preoperative jaundice & & & 0.608 & & & \\
\hline No & 1 & & & & & \\
\hline Yes & 0.912 & $0.640-1.299$ & & & & \\
\hline Alcohol abuse & & & 0.482 & & & \\
\hline No & 1 & & & & & \\
\hline Yes & 1.17 & $0.755-1.813$ & & & & \\
\hline Diabetes mellitus & & & 0.462 & & & \\
\hline No & 1 & & & & & \\
\hline Yes & 1.19 & $0.748-1.894$ & & & & \\
\hline Previous abdominal surgery history & & & 0.913 & & & \\
\hline No & 1 & & & & & \\
\hline Yes & 0.976 & $0.626-1.521$ & & & & \\
\hline Preoperative biliary decompression & & & 0.176 & & & \\
\hline No & 1 & & & & & \\
\hline Yes & 1.302 & $0.888-1.910$ & & & & \\
\hline Operation time & & & 0.028 & & & 0.04 \\
\hline$\leq 330 \min$ & 1 & & & 1 & & \\
\hline$>330 \mathrm{ml}$ & 1.622 & $1.055-2.494$ & & 1.635 & $1.022-2.617$ & \\
\hline Intraoperative RBC transfusion & & & 0.273 & & & \\
\hline
\end{tabular}


Table 4 Logistic Regression Analysis of factors affecting POPF (Continued)

\begin{tabular}{|c|c|c|c|c|c|c|}
\hline \multirow[t]{2}{*}{ Parameter } & \multicolumn{2}{|c|}{ Univariate Analysis } & \multirow[t]{2}{*}{$P$} & \multicolumn{2}{|c|}{ Multivariate Analysis } & \multirow[t]{2}{*}{$P$} \\
\hline & Odds Ratio & $95 \% \mathrm{Cl}$ & & Odds Ratio & $95 \% \mathrm{Cl}$ & \\
\hline No & 1 & & & & & \\
\hline Yes & 1.345 & $0.791-2.286$ & & & & \\
\hline \multicolumn{2}{|c|}{ Pancraticoenteric anastomosis method } & & 0.037 & & & 0.001 \\
\hline Pancreticojejunostomy (PJ) & 1 & & & 1 & & \\
\hline Pancreticogastrostomy (PG) & 1.529 & $1.025-2.279$ & & 0.323 & $0.163-0.639$ & \\
\hline \multicolumn{2}{|c|}{ Combined with vascular resection } & & 0.232 & & & \\
\hline No & 1 & & & & & \\
\hline Yes & 0.531 & $0.188-1.498$ & & & & \\
\hline
\end{tabular}

expected to utilize different forms of PA depending on pancreatic texture and main pancreatic duct in selected situations, which might be a potential solution to evade problem of POPF. PJ is the commonly preferred anastomosis method. Many techniques have been proposed for the reconstruction of pancreatic digestive continuity to prevent complications after PD. [10-12] PG anastomosis has an excellent blood supply, less tension in the anastomosis, and a thick stomach wall, which facilitate the establishment of a sound anastomosis [13]. Furthermore, the acid milieu of the stomach and the absence of enterokinase protect the anastomosis from autodigestion by inactivating the pancreatic proenzymes [14]. Previous studies reported contradictory results regarding the impact of PG versus PJ on the postoperative fistula rate [15-17]. Recently, reconstruction by PG was associated with lower postoperative pancreatic and biliary fistula rates [18]. These principles include good exposure and visualization, the use of a fine, nonstrangulating suture to produce a water-tight patent anastomosis, preservation of the blood supply, tension-free fixation of the gastrointestinal tract to the pancreas, and coverage of the transected pancreas [19]. The present study identified the morbidity of GJ was higher than that of PG significantly for patients with soft pancreas. Generally, it recommended that PG was an optimal approach for these patients.

This study contained 52 patients (9.8\%) with clinically relevant PF after PD, which was highly consistent with previous studies. A grade A POPF was not considered clinically important; thus, only grade $\mathrm{B} / \mathrm{C}$ should account for the incidence of clinically relevant POPF [20].

Table 5 Subgroup analysis according to pancreas texture: PG vs PJ

\begin{tabular}{|c|c|c|c|c|c|c|}
\hline & \multicolumn{3}{|c|}{ For hard pancreas texture } & \multicolumn{3}{|c|}{ For soft pancreas texture } \\
\hline & PJ(132pts) & PG(56pts) & $p$ & PJ(18pts) & PG(308pts) & $p$ \\
\hline Operation time (min) & $293.0 \pm 56.1$ & $312.6 \pm 62.0$ & 0.035 & $321.3 \pm 74.1$ & $284.4 \pm 65.0$ & 0.021 \\
\hline Intraoperative blood loss (ml) & $270.8 \pm 191.7$ & $253.6 \pm 151.9$ & 0.550 & $313.9 \pm 137.0$ & $233.3 \pm 172.9$ & 0.053 \\
\hline POPF & $28.8 \%$ & $16.1 \%$ & 0.066 & $61.1 \%$ & $47.4 \%$ & 0.258 \\
\hline CR-POPF & $9.1 \%$ & $1.8 \%$ & 0.071 & $27.8 \%$ & $11.0 \%$ & 0.033 \\
\hline Intraoperative RBC transfusion & $12.9 \%$ & $12.5 \%$ & 0.943 & $16.7 \%$ & $11.7 \%$ & 0.527 \\
\hline PPH & $14.4 \%$ & $16.1 \%$ & 0.768 & $22.2 \%$ & $13.6 \%$ & 0.298 \\
\hline Postoperative RBC transfusion & $19.7 \%$ & $21.4 \%$ & 0.787 & $50.0 \%$ & $23.7 \%$ & 0.012 \\
\hline Postoperative hospital stay (days) & $20.1 \pm 11.3$ & $22.4 \pm 10.2$ & 0.207 & $32.5 \pm 12.8$ & $24.5 \pm 15.0$ & $0.02 \varepsilon$ \\
\hline Postoperative complications & $48.5 \%$ & $53.6 \%$ & 0.524 & $77.8 \%$ & $64.6 \%$ & 0.315 \\
\hline Reoperation & $0.0 \%$ & $1.8 \%$ & 0.298 & $5.6 \%$ & $4.5 \%$ & 0.582 \\
\hline Postoperative percutaneous drainage & $6.1 \%$ & $5.4 \%$ & 0.851 & $16.7 \%$ & $12.7 \%$ & 0.714 \\
\hline Dilated main pancreaitc duct(>3 mm) & $71.2 \%$ & $39.3 \%$ & $<0.001$ & $22.2 \%$ & $8.8 \%$ & 0.079 \\
\hline Readmission & $1.5 \%$ & $0.0 \%$ & 1.000 & $0.0 \%$ & $1.3 \%$ & 1.000 \\
\hline Postoperative abdominal infection & $9.1 \%$ & $10.7 \%$ & 0.729 & $27.8 \%$ & $19.8 \%$ & 0.413 \\
\hline
\end{tabular}

$P G$ pancreaticogastrostomy, $P J$ pancreaticojejunostomy, $P O P F$ postoperative pancreatic fistula, $C R-P O P F$ clinically relevant postoperative pancreatic fistula, $P P H$ post-pancreatectomy hemorrhage, $R B C$ red blood cell 
Table 6 Subgroup analysis according to main pancreatic duct diameter: PG vs PJ

\begin{tabular}{|c|c|c|c|c|c|c|}
\hline & For dilated ma & increatic duct(> & & For normal m & ancreatic $\operatorname{duct}(\leq$ & \\
\hline & PJ(98pts) & PG(49pts) & $p$ & PJ(52pts) & PG(315pts) & $p$ \\
\hline Operation time (min) & $290.3 \pm 58.3$ & $300.5 \pm 61.6$ & 0.328 & $307.9 \pm 59.0$ & $286.9 \pm 65.7$ & 0.031 \\
\hline Intraoperative blood loss (ml) & $264.3 \pm 193.7$ & $277.6 \pm 160.1$ & 0.680 & $298.1 \pm 170.6$ & $230.0 \pm 170.6$ & 0.008 \\
\hline POPF & $20.4 \%$ & $14.3 \%$ & 0.366 & $55.8 \%$ & $47.0 \%$ & 0.240 \\
\hline CR-POPF & $7.1 \%$ & $2.0 \%$ & 0.269 & $19.2 \%$ & $10.8 \%$ & 0.083 \\
\hline Intraoperative RBC transfusion & $11.2 \%$ & $12.2 \%$ & 0.855 & $17.3 \%$ & $11.7 \%$ & 0.262 \\
\hline PPH & $14.3 \%$ & $10.2 \%$ & 0.487 & $17.3 \%$ & $14.6 \%$ & 0.613 \\
\hline Postoperative RBC transfusion & $17.3 \%$ & $20.4 \%$ & 0.651 & $34.6 \%$ & $23.8 \%$ & 0.097 \\
\hline Postoperative hospital stay (days) & $18.4 \pm 10.3$ & $18.4 \pm 6.9$ & 0.985 & $27.8 \pm 13.0$ & $25.1 \pm 15.1$ & 0.228 \\
\hline Postoperative complications & $39.8 \%$ & $44.9 \%$ & 0.554 & $75.0 \%$ & $65.7 \%$ & 0.187 \\
\hline Reoperation & $0.0 \%$ & $0.0 \%$ & - & $1.9 \%$ & $4.8 \%$ & 0.711 \\
\hline Postoperative percutaneous drainage & $5.1 \%$ & $4.1 \%$ & 1.000 & $11.5 \%$ & $12.7 \%$ & 0.815 \\
\hline Hard pancreatic gland texture & $95.9 \%$ & $44.9 \%$ & $<0.001$ & $73.1 \%$ & $10.8 \%$ & $<0.001$ \\
\hline Readmission & $1.5 \%$ & $0.0 \%$ & 1.000 & $0.0 \%$ & $1.0 \%$ & 1.000 \\
\hline Postoperative abdominal infection & $2.0 \%$ & $2.0 \%$ & 1.000 & $21.2 \%$ & $20.3 \%$ & 0.890 \\
\hline
\end{tabular}

$P G$ pancreaticogastrostomy, $P J$ pancreaticojejunostomy, $P O P F$ postoperative pancreatic fistula, $C R-P O P F$ clinically relevant postoperative pancreatic fistula, $P P H$ post-pancreatectomy hemorrhage, $R B C$ red blood cell

The prevention of clinically relevant POPF may partially depend on the prompt healing of pancreaticodigestive tract anastomoses, which is attributed to the immediate recovery from a minor pancreatic fistula originating from the pancreatic branch duct or parenchyma at the pancreas surface [5]. Prophylactic drains after pancreatic surgery allow physicians to monitor the occurrence of intra-abdominal bleeding and to detect and drain a pancreatic, biliary, or enteric fistula [21]. Intermittent irrigation aimed to dilute the concentration of intraabdominal amylase level, which is effective in preventing damage caused by the erosive retention of pancreatic secretions. For symptomatic abdominal collection fluid or abdominal abscess, percutaneous puncture and drainage was the preferred procedure. The reported success rate of the conservative treatment of a POPF is approximately $80 \%$. The relaparotomy should be performed only when patients presented a high output fistula and severe sepsis or haemorrhage and cannot be managed by other means [22].

The results were consistent with the literature that reported a significantly elevated risk of post-PD bleeding in patients with pancreatic fistulas [23, 24]. It was also confirmed that pancreatic leakage and intra-abdominal abscess were correlated to post-PD bleeding [25]. Therefore, any procedure that can prevent pancreatic fistula or intra-abdominal abscess can decrease the post-PD bleeding rate. Prophylactic irrigation around a PJ was reported to possibly decrease the incidence of pancreatic fistulas and infectious complications [26]. It was routinely performed a low- speed intermittent irrigation was added when the drain fluid turned turbid with sediment.

\section{Conclusions}

Individualized pancreaticoenteric anastomosis should be determined based on the pancreatic texture and diameter of the main pancreatic duct. The appropriate anastomosis and postoperative management could prevent mortality.

\section{Supplementary information}

Supplementary information accompanies this paper at https://doi.org/10. 1186/s12893-020-00791-y.

\section{Additional file 1}

\section{Abbreviations}

CR-POPF: Clinically relevant postoperative pancreatic fistula; PG: Pancreaticogastrostomy; PJ: Pancreaticojejunostomy; BMI: Body mass index; PD: Pancreaticoduodenectomy; POPF: Postoperative pancreatic fistula; PA: Pancreaticoenteric anastomosis; ASA: American Society of Anaesthesiologists

\section{Acknowledgements}

Not applicable.

\section{Authors' contributions}

BCX contributed to the conception and design. KW, QB and HWW are responsible for the provision of the study materials and data collection. KMJ and WL contributed to the data analysis and interpretation and draft writing equally. All authors read and approved the final manuscript.

\section{Funding}

Not applicable. 


\section{Availability of data and materials}

The datasets generated and/or analyzed during the current study are not publicly available due to protecting individual patient privacy but are available from the corresponding author on reasonable request.

\section{Ethics approval and consent to participate}

This study was approved by the Clinical Research Ethics Committee of the Peking University Cancer Hospital and was performed in compliance with the Helsinki Declaration. Written informed consent was obtained from all patients.

\section{Consent for publication}

Not Applicable.

\section{Competing interests}

The authors declare that they have no conflict of interest.

Received: 19 May 2020 Accepted: 9 June 2020

Published online: 22 June 2020

\section{References}

1. He J, Ahuja N, Makary MA, et al. 2564 resected periampullary adenocarcinomas at a single institution: trends over three decades. HPB (Oxford). 2014:16:83-90.

2. Cameron $\mathrm{J}$, He J. Two thousand consecutive pancreaticoduodenectomies. J Am Coll Surg. 2015;220:530-6.

3. Kawakatsu S, Inoue Y, Mise Y, et al. Comparison of pancreatojejunostomy techniques in patients with a soft pancreas: Kakita anastomosis and Blumgart anastomosis. BMC Surg. 2018;18:88

4. Hanaki T, Uejima C, Amisaki M, et al. The attenuation value of preoperative computed tomography as a novel predictor for pancreatic fistula after pancreaticoduodenectomy. Surg Today. 2018;48:598-608.

5. Takahashi S, Gotohda N, Kato Y, et al. Measure of pancreas transection and postoperative pancreatic fistula. J Surg Res. 2016;202:276-83.

6. Miura F, Asano T, Amano H, et al. Management of postoperative arteria hemorrhage after pancreato-biliary surgery according to the site of bleeding: re-laparotomy or interventional radiology. J Hepato-BiliaryPancreat Surg. 2009;16:56-63.

7. Dindo D, Demartines N, Clavien PA. Classification of surgical complications: a new proposal with evaluation in a cohort of 6336 patients and results of a survey. Ann Surg. 2004;240:205-13.

8. Blanc T, Cortes A, Goere D, et al. Hemorrhage after pancreaticoduodenectomy: when is surgery still indicated? Am J Surg. 2007; 194:3-9.

9. Shrikhande SV, Sivasanker M, Vollmer CM, et al. Pancreatic anastomosis after pancreatoduodenectomy: a position statement by the international study Group of Pancreatic Surgery (ISGPS). Surgery. 2017;161:1221-34.

10. Sakorafas $\mathrm{GH}$, Friess $\mathrm{H}$, Balsiger BM, et al. Problems of reconstruction during pancreatoduodenectomy. Dig Surg. 2001;18:363-9.

11. Yeo CJ, Cameron JL, Lillemoe KD, et al. Does prophylactic octreotide decrease the rates of pancreatic fistula and other complications after pancreaticoduodenectomy? Results of a prospective randomized placebocontrolled trial. Ann Surg. 2000;232:419-29.

12. Peng SY, Wang JW, Lau WY, et al. Conventional versus binding pancreaticojejunostomy after pancreaticoduodenectomy: a prospective randomized trial. Ann Surg. 2007;245:692-8.

13. Aranha GV, Hodul P, Golts $\mathrm{E}$, et al. A comparison of pancreaticogastrostomy and pancreaticojejunostomy following pancreaticoduodenectomy. $J$ Gastrointest Surg. 2003:7:672-82.

14. Fang WL, Shyr YM, Su CH, et al. Comparison between pancreaticojejunostomy and pancreaticogastrostomy after pancreaticoduodenectomy. J Formos Med Assoc. 2007;106:717-27.

15. Wellner U, Makowiec F, Fischer E, et al. Reduced postoperative pancreatic fistula rate after pancreatogastrostomy versus pancreaticojejunostomy. J Gastrointest Surg. 2009;13:745-51

16. Wente MN, Shrikhande SV, Muller MW, et al. Pancreaticojejunostomy versus pancreaticogastrostomy: systematic review and meta-analysis. Am J Surg. 2007:193:171-83.

17. Fathy O, Abdel-Wahab M, Elghwalby $\mathrm{N}$, et al. Surgical management of periampullary tumors: a retrospective study. Hepatogastroenterology. 2008;55: 1463-9.
18. Menahem B, Guittet $L$, Mulliri A, et al. Pancreaticogastrostomy is superior to pancreaticojejunostomy for prevention of pancreatic fistula after pancreaticoduodenectomy: an updated meta-analysis of randomized controlled trials. Ann Surg. 2005;61:882-7.

19. Adams DB. The pancreatic anastomosis: the danger of a leak, which anastomotic technique is better? J Gastrointest Surg. 2009;13:1182-3.

20. Pedrazzoli S, Liessi G, Pasquali C, et al. Postoperative pancreatic fistulas: preventing severe complications and reducing reoperation and mortality rate. Ann Surg. 2009;249:97-104.

21. Oguro S, Yoshimoto J, Imamura $H$, et al. Three hundred and sixty-eight consecutive pancreaticoduodenectomies with zero mortality. J Hepatobiliary Pancreat Sci. 2017;24:226-34.

22. Alexakis N, Sutton R, Neoptolemos JP. Surgical treatment of pancreatic fistula. Dig Surg. 2004;21:262-74.

23. Yekebas EF, Wolfram L, Cataldegirmen G, et al. Postpancreatectomy hemorrhage: diagnosis and treatment: an analysis in 1669 consecutive pancreatic resections. Ann Surg. 2007;246:269-80.

24. Choi SH, Moon HJ, Heo JS, et al. Delayed hemorrhage after pancreaticoduodenectomy. J Am Coll Surg. 2004;199:186-91.

25. Wei HK, Wang SE, Shyr YM, et al. Risk factors for postpancreaticoduodenectomy bleeding and finding an innovative approach to treatment. Dig Surg. 2009:26:297-305.

26. Nakano H, Asakura T, Sakurai J, et al. Prophylactic irrigation around a pancreaticojejunostomy for the treatment of a pancreatic fistula after a pancreaticoduodenectomy in patients with a risky pancreatic remnant. Hepatogastroenterology. 2008;55:717-21.

\section{Publisher's Note}

Springer Nature remains neutral with regard to jurisdictional claims in published maps and institutional affiliations.

Ready to submit your research? Choose BMC and benefit from:

- fast, convenient online submission

- thorough peer review by experienced researchers in your field

- rapid publication on acceptance

- support for research data, including large and complex data types

- gold Open Access which fosters wider collaboration and increased citations

- maximum visibility for your research: over $100 \mathrm{M}$ website views per year

At BMC, research is always in progress.

Learn more biomedcentral.com/submissions 